This item was submitted to Loughborough's Research Repository by the author.

Items in Figshare are protected by copyright, with all rights reserved, unless otherwise indicated.

\title{
The hydrodynamics of landslide tsunamis: current analytical models and
} future research directions

PLEASE CITE THE PUBLISHED VERSION

http://dx.doi.org/10.1007/s10346-016-0680-z

\section{PUBLISHER}

(C) Springer Verlag (Germany)

\section{VERSION}

AM (Accepted Manuscript)

\section{PUBLISHER STATEMENT}

This work is made available according to the conditions of the Creative Commons Attribution-NonCommercialNoDerivatives 4.0 International (CC BY-NC-ND 4.0) licence. Full details of this licence are available at: https://creativecommons.org/licenses/by-nc-nd/4.0/

\section{LICENCE}

CC BY-NC-ND 4.0

\section{REPOSITORY RECORD}

Renzi, Emiliano, and Paolo Sammarco. 2019. "The Hydrodynamics of Landslide Tsunamis: Current Analytical Models and Future Research Directions”. figshare. https://hdl.handle.net/2134/20350. 


\title{
The hydrodynamics of landslide tsunamis: current analytical models and future research directions.
}

\author{
Emiliano Renzi · Paolo Sammarco
}

Received: date / Accepted: date

\begin{abstract}
Landslide generated tsunamis are lesser-known yet equally destructive than earthquake tsunamis. Indeed, the highest tsunami wave recorded in recent history was generated by a landslide in Lituya Bay (Alaska, July 9, 1958) and produced runup in excess of $400 \mathrm{~m}$. In this paper, we review the state of the art of landslide tsunami analytical modelling. Within the framework of a linearised shallowwater theory, we illustrate the dynamics of landslide tsunami generation and propagation along beaches and around islands. Finally, we highlight some intriguing new directions in the analytical modelling of landslide tsunamis to support early warning systems.
\end{abstract}

Keywords Landslide tsunamis · Analytical Modelling · Fluid Dynamics

\section{Introduction}

Landslide tsunamis are transient surface gravity waves generated by mass failures at the margins of water bodies. Tsunamis can be generated as a subaerial mass enters the water, such as the 1963 Vajont event in Italy (Panizzo et al 2005; Di Risio and Sammarco 2008), or as a submarine mass failure (SMF) pushes water ahead, like in the 1998 Papua New Guinea event (Tappin et al 2008). While the hydrodynamics of earthquake tsunamis is well understood at present, the generation and propagation of landslide tsunamis is instead less fathomed

E. Renzi

Department of Mathematical Sciences, Loughborough University, Loughborough, Leics LE11 3TU, UK

Tel.: +44 1509223186

E-mail: e.renzi@lboro.ac.uk

P. Sammarco

Department of Civil and Computer Science Engineering, University of Rome Tor Vergata, Via del Politecnico 1, 00133 Rome, Italy
(Liu et al 2005; Kanoglu and Synolakis 2015). Indeed, modelling landslide tsunamis is intrinsically challenging as it involves a time-dependent bottom deformation in the same region where the waves are generated and propagate. In this paper, we shall review the analytical models of Sammarco and Renzi (2008), Renzi and Sammarco (2010) and Renzi and Sammarco (2012), which have become benchmark models for numerical codes (Romano et al 2013; Dias et al 2014; Stefanakis et al 2014) and statistical emulations (Sarri et al 2012) of landslide tsunamis. Analytical models provide an invaluable tool in the science of tsunami modelling, for they allow one to obtain a sound physical understanding of the wave dynamics and to carry out parametric investigations on the influence of the system main parameters on the maximum wave runup.

The paper is organised as follows. First, we shall discuss the evolution of landslide tsunami analytical modelling, from the first simplified attempts to forced two-horizontaldimensions solutions (Section 2). Then we shall illustrate the hydrodynamics of landslide tsunami generation and propagation based on those analytical solutions (Section 3). Finally, we shall discuss the practical importance (and limits) of our analytical results and introduce new research ideas based upon them (Section 4).

\section{State of the art of landslide tsunami modelling}

The hydrodynamic modelling of landslide generated tsunamis is quite a recent branch of fluid dynamics. The Lituya Bay first and the devastating Papua New Guinea (PNG) tsunami on July 17,1998 , after, drove the international tsunami community to recognise the potential hazard of SMFs, starting a systematic approach to the modelling of landslide tsunami hydrodynamics. The PNG tsunami was generated by an underwater sediment slump just offshore, with a total volume of 
$6.4 \mathrm{~km}^{3}$ (Farrell et al 2015). The waves reached a maximum runup of about $15 \mathrm{~m}$, hitting a $15 \mathrm{~km}$ section of northern PNG known as the Sissano Lagoon and killing more than 2000 people (Tappin et al 2008; Farrell et al 2015). One of the striking features of the PNG tsunami was the unexpected concentration of the runup along a relatively narrow stretch of the coastline, which could not be explained with traditional earthquake tsunami models (Kanoglu and Synolakis 2015). The PNG event was characterised by three distinctive characteristics: (1) unexpectedly large wave amplitude, (2) delayed time of arrival and (3) focussing of coastal inundation along a limited stretch. Such characteristics are usually not associated with earthquake tsunamis and indeed are proper of landslide generated tsunamis. During a seismic event, the vertical seafloor dislocation can reach several metres and the fault can extend up to $1000 \mathrm{~km}$ laterally. On the contrary, the vertical seafloor deformation associated with a landslide depends on the dimensions of the landslide mass and on the distance travelled by the dislocation, both of the order of $100 \mathrm{~m}$. The slide lateral extent is usually contained within a few kilometres (Bardet et al 2003). Because of such different length scales, earthquake tsunamis have longer period and can travel substantially larger distances than landslide tsunamis. The latter, however, focus along narrow stretches of the coastline and can induce larger runups locally. Indeed the largest known tsunami wave in modern times was generated by the landslide in Lituya Bay (Alaska, July 9, 1958), which produced runup in excess of $400 \mathrm{~m}$ (Kanoglu and Synolakis 2015).

A challenging aspect of landslide tsunami modelling is the dependence of the transient wave field on the actual time history of the seafloor deformation. In an attempt of simplifying such complex dynamics, Watts et al (2003) initially neglected the direct bottom forcing and assigned a hot-start condition at the free surface from SMF tsunami generation. Such an initial condition was then to be implemented in tsunami propagation and inundation models. Later, Sammarco and Renzi (2008) demonstrated that no analytical proof of the validity of the hot-start approach could be given, suggesting that such simplified models be used only for quick runup assessment. Indeed, Liu et al (2003) were among the first to recognise the importance of including the time history of the seafloor deformation in landslide tsunami modelling. Liu et al (2003) derived a one-dimensional analytical model of waves generated by a moving block down a sloping beach, by including the time history of the block motion as a forcing term directly into the linear shallow water equation. Subsequent numerical investigation by Lynett and Liu (2005) on a three-dimensional plane beach showed that a sliding mass is in fact able to generate two different wave fields. At the earliest times following the landslide motion, Lynett and Liu (2005) observed not only fast decaying offshore waves, but also travelling waves propagating along the coastline. Such longshore motion eventually becomes predominant, in the fashion of transient propagating edge waves. The numerical results of Lynett and Liu (2005) highlighted the need to develop an appropriate analytical two-horizontal-dimension (2HD) model to explain such dynamics. Following the suggestion of Lynett and Liu (2005), Sammarco and Renzi (2008), Renzi and Sammarco (2010) and Renzi and Sammarco (2012) developed fully 2HD analytical models of landslide tsunami generation and propagation along a plane beach and around a conical island, induced by a sliding solid block. By using the forced linear shallow water equation, Sammarco and Renzi (2008) derived the analytical form of both the offshore component and the transient edge waves travelling along the shoreline of a plane beach. Sammarco and Renzi (2008) showed analytically that for landslide-induced tsunamis along a sloping beach the larger waves are not in the front of the wavetrain, but are shifted toward the middle of it. This behaviour is in sharp contrast with that of transient waves generated and propagating in water of constant depth, like earthquake tsunamis, where the larger waves are usually in front of the wave train (Chapter 2 of Mei et al 2005). By applying the same analytical model to a conical island, Renzi and Sammarco (2010) derived a new solution to the forced linear shallow-water equation in terms of confluent Heun functions. Such solution shows that on a conical island refraction is reduced and landslide induced waves are not completely trapped along the shoreline. Therefore, around a conical island no perfectly trapped edge waves are generated by the landslide and waves propagate also in the offshore direction. Nevertheless, quasi-trapped waves are still able to produce enhanced runup around the island. Finally, Renzi and Sammarco (2012) extended the original plane beach model of Sammarco and Renzi (2008) to consider the influence of the landslide shape and the continental shelf on the wave field. Renzi and Sammarco (2012) showed that the presence of irregularities in the shape of the landslide favours the generation of spiky double-crested waves, which carry a more destructive potential. On the other hand, the presence of the continental shelf reduces the number of spectral components that are excited by the landslide with respect to an indefinite plane beach and may be beneficial in mitigating the severity of the tsunami. In the following section we shall review the 2HD mathematical models of landslide generated tsunamis and the most important practical results which derive from their analytical solution. Current and future research directions stemming from such models will be further discussed in Section 4. 


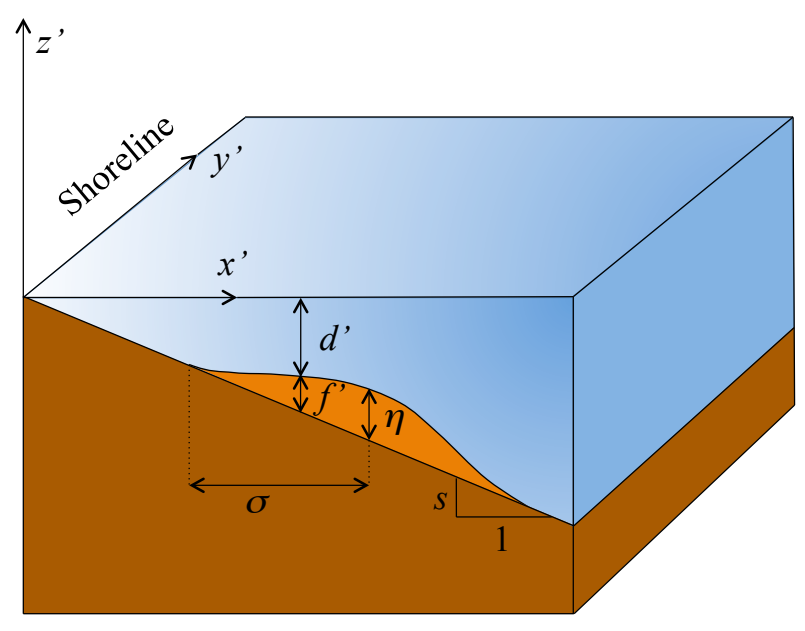

Fig. 1 Plane beach and landslide in physical variables.

\section{Two-horizontal dimension models}

3.1 Plane beach model (Sammarco and Renzi 2008; Renzi and Sammarco 2012)

A feature of the plane beach geometry is its ability to trap waves generated on it. This results in energy focussing along the beach, which induces unexpectedly high runups (Kanoglu and Synolakis 2015). Sammarco and Renzi (2008) showed that such a behaviour is due to the occurrence of transient dispersive shallow water waves, otherwise non-dispersive on a flat bottom, propagating along the shoreline.

Mathematical formulation Let us consider an indefinite plane beach of given slope $s$. The effect of a flat continental shelf at the end of a finite beach will be analysed later in this section. Set a Cartesian reference system with the $y^{\prime}$ axis along the shoreline, the $x^{\prime}$ axis orthogonal to $y^{\prime}$, and the $z^{\prime}$ axis pointing upwards from the $\left(x^{\prime}, y^{\prime}\right)$ plane, as shown in Fig. 1. The landslide is modelled as a rigid sliding block, symmetric with respect to the $x^{\prime}$ axis. Hence the induced wave field will be symmetric with respect to $x^{\prime}$ too, so that it suffices to solve the governing equations only in the sector $y^{\prime}>0$. The landslide has maximum vertical height $\eta$ and characteristic horizontal length $2 \sigma$ (see again Fig. 1). We shall assume that the slope is mild, $s \ll 1$, and that the slide is thin, $\eta / \sigma \ll 1$, such as in the case of the Stromboli landslide tsunami (Di Risio et al 2009a,b; Cecioni et al 2011). This excludes large-scale flank collapses, where strong shoreline motions, wave breaking and possible dissipation effects during propagation occur (Tehranirad et al 2015), which are not considered in this paper. Assuming a mild slope and a thin slide allows us to use the linear inviscid shallow-water theory for forced waves on an incline (Renzi 2010). The governing equation of motion reads:

$\frac{\partial^{2} \zeta^{\prime}}{\partial t^{\prime 2}}-g \nabla \cdot\left(h^{\prime} \nabla \zeta^{\prime}\right)=\frac{\partial^{2} f^{\prime}}{\partial t^{\prime 2}}$,

where $\nabla=\left[\partial / \partial x^{\prime}, \partial / \partial y^{\prime}\right]$ is the nabla operator. $\zeta^{\prime}\left(x^{\prime}, y^{\prime}, t^{\prime}\right)$ is the free-surface elevation, $g$ is the gravity acceleration, $t^{\prime}$ is time and $h^{\prime}=s x^{\prime}=d^{\prime}+f^{\prime}\left(x^{\prime}, y^{\prime}, z^{\prime}\right)$, where $d^{\prime}$ is the actual bottom depth. $f^{\prime}\left(x^{\prime}, y^{\prime}, t^{\prime}\right)$ is a prescribed forcing term which introduces the time history of the seafloor deformation in the equation of motion (1). The latter can be solved once appropriate boundary conditions are prescribed. We require that the free-surface elevation $\zeta^{\prime}$ be finite at the shoreline $x^{\prime}=0$ and as $x^{\prime} \rightarrow \infty$, and that the fluid is initially at rest: $\zeta^{\prime}\left(x^{\prime}, y^{\prime}, 0\right)=\partial \zeta^{\prime} / \partial t^{\prime}\left(x^{\prime}, y^{\prime}, 0\right)=0$. The full solution of such a boundary-value problem for $\zeta^{\prime}\left(x^{\prime}, y^{\prime}, t^{\prime}\right)$ was obtained for any generic disturbance $f^{\prime}\left(x^{\prime}, y^{\prime}, t^{\prime}\right)$. Application of the cosine Fourier transform along $y^{\prime}$ (Chapter 7.6, Mei 1997) and the method of variation of parameters to the forced governing equation (Eq. 1) yield the non-dimensional form of the freesurface elevation:

$\zeta(x, y, t)=\frac{2}{\pi} \sum_{n=0}^{\infty} \int_{0}^{\infty} e^{-k x} L_{n}(2 k x) T_{n}(k, t) \cos (k y) d k$,

where

$\left\{\begin{array}{l}x \\ y\end{array}\right\}=\frac{1}{\sigma}\left\{\begin{array}{l}x^{\prime} \\ y^{\prime}\end{array}\right\}, t=\sqrt{g s / \sigma} t^{\prime},\left\{\begin{array}{l}\zeta \\ f\end{array}\right\}=\frac{1}{\eta}\left\{\begin{array}{l}\zeta^{\prime} \\ f^{\prime}\end{array}\right\}$

are non-dimensional variables. In Eq. 2 , the $L_{n} \mathrm{~s}$ are the Laguerre polynomials of integer order $n$ (Mei et al 2005), while the $T_{n} \mathrm{~s}$ are given by

$$
\begin{aligned}
T_{n}(k, t) & =\frac{2 k}{\omega_{n}} \int_{0}^{\infty} \int_{0}^{t} e^{-k \alpha} L_{n}(2 k \alpha) \\
& \times \hat{f}_{\tau \tau}(\alpha, k, \tau) \sin \left[\omega_{n}(t-\tau)\right] d \tau d \alpha .
\end{aligned}
$$

In the latter expression, $\hat{f}_{\tau \tau}$ is the second-order time derivative of the Fourier transform of the bottom dislocation. The $\omega_{n} \mathrm{~s}$ are defined by the dispersion relation

$\omega_{n}=\sqrt{k(2 n+1)}$,

which relates the wave frequency $\omega_{n}$ of the $n$th wave mode to the wavenumber $k$ along the shoreline. Note that the dispersion relation of shallow-water waves over a plane beach, Eq. 5 , is very different from that of shallow-water waves propagating over a bottom of constant depth $h$, i.e. $\omega=k \sqrt{g h}$ (Mei et al 2005). Over a flat bottom, shallow-water waves travel all at the same phase speed $c=\omega / k=\sqrt{g h}$, so that frequency dispersion is absent. Along a plane beach, instead, waves travel at the phase speed $c_{n}=\omega_{n} / k=\sqrt{(2 n+1) / k}$, see Eq. 5, which depends on the wavenumber $k$. Longer waves $(k \rightarrow 0)$ travel faster $\left(c_{n} \rightarrow \infty\right)$ and are followed by a train of shorter waves $\left(k \rightarrow \infty\right.$ implies $\left.c_{n} \rightarrow 0\right)$, exhibiting a dispersive behaviour. This model provides an analytical demonstration of the dispersive nature of landslide tsunami 

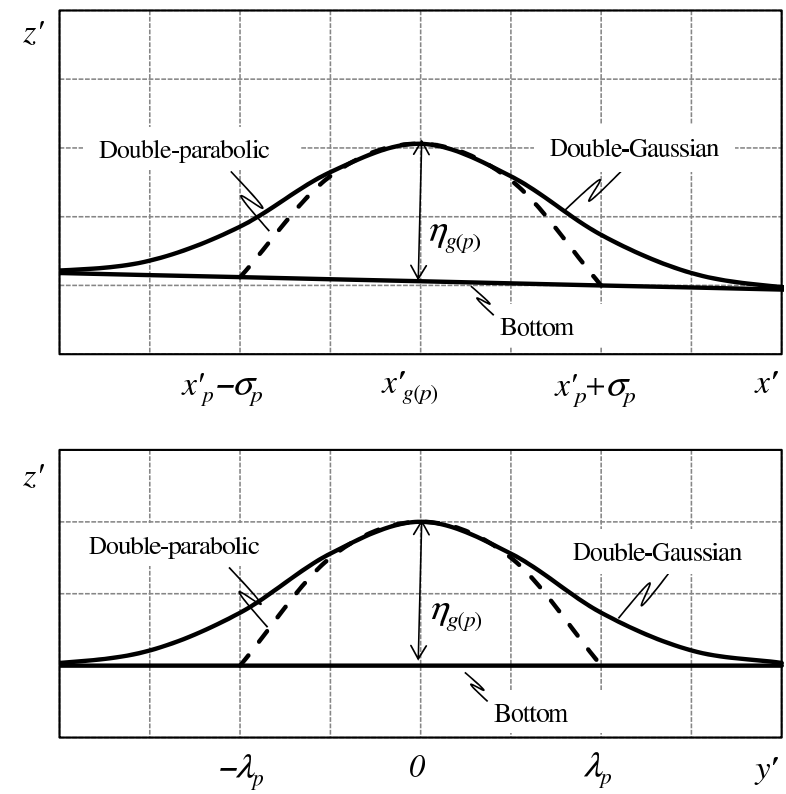

Fig. 2 Vertical cross sections of the double Gaussian landslide (solid line) and the double parabolic slide (dashed line). Upper panel: section in the offshore direction. Lower panel: longshore direction. Parameters: $\sigma_{g}=\sigma_{p}, \eta_{g}=\eta_{p}$. Vertical dimensions are exaggerated for easiness of reading. After Renzi and Sammarco (2012).

waves propagating over an inclined bottom. The numerical simulations of Ma et al (2012) and Ma et al (2013) recently confirmed the importance of frequency dispersion in landslide tsunami propagating on a plane beach.

Note from Eq.s 2-4 that the final form of the free-surface elevation $\zeta$ depends on the shape of the landslide and on its law of motion via the function $f(x, y, t)$. Renzi and Sammarco (2012) analysed the effects of two different seafloor movements. One is a translating double Gaussian landslide of the form

$f_{g}(x, y, t)=\exp \left[-\left(x-x_{g}-u_{g} t\right)^{2}\right] \exp \left(-\frac{\sigma_{g}}{\lambda_{g}} y\right)$,

where the subscript $g$ denotes quantities relevant to the double Gaussian slide. Such a slide moves offshore as a rigid body, its centre being initially at $x=x_{g}$. Since the slide is thin and the slope is mild, the uniformly accelerated motion of the slide down the incline is approximated as a uniform motion with constant speed $u_{g}$ (Di Risio et al 2009a; Renzi and Sammarco 2012). Vertical cross sections of the double Gaussian slide are shown in the parametric plots of Fig. 2. The second landslide shape considered by Renzi and Sammarco (2012) is a finite-length double parabolic slide:

$$
\begin{aligned}
f_{p}(x, y, t) & =\left(x-x_{p}-u_{p} t+1\right)\left(x_{p}+u_{p} t+1-x\right) \\
& \times\left(1-\frac{\sigma_{p}}{\lambda_{p}} y\right)\left(1+\frac{\sigma_{p}}{\lambda_{p}} y\right) H\left(x-x_{p}-u_{p} t+1\right) \\
& \times H\left(x_{p}+u_{p} t+1-x\right) H\left(\lambda_{p} / \sigma_{p}-y\right) .
\end{aligned}
$$

In the latter, the subscript $p$ denotes quantities relevant to the double parabolic slide. $H$ is the Heaviside step function, which is used for cutting the slide to a finite length along both $x$ and $y$. Again, only $y>0$ is considered because of symmetry. Such a slide has a finite rectangular footprint, in contrast to the double Gaussian slide (Eq. 6) which in fact decays to infinity in both directions. Note that the double parabolic slide of Eq. 7 moves with constant offshore speed $u_{p}$, its centre being initially at $x=x_{p}$. Vertical cross sections of the double parabolic block are shown in Fig. 2. In the following, we shall show the dynamics of landslide tsunami generation and propagation in the case of a double Gaussian slide along a plane beach (Eq. 6). Next, we shall comment on the influence of the slide shape and continental shelf.

Tsunami generation and propagation Figure 3 shows four 3D snapshots of the tsunami generated by the double Gaussian landslide (Eq. 6) of Fig. 2 , with dimensions $\sigma_{g}=0.37$ $\mathrm{m}, \eta_{g}=0.045 \mathrm{~m}, \lambda_{g}=0.185 \mathrm{~m}$ and mean speed $u_{g}^{\prime}=1 \mathrm{~m} / \mathrm{s}$, starting from $x_{g}^{\prime}=0 \mathrm{~m}$. This corresponds to the landslide being initially half-submerged. The beach slope is $s=1 / 3$ (1 vertical, 3 horizontal). Such dimensions are similar to those of the physical model used in the laboratory tests of Di Risio et al (2009a), which in turn are roughly representative of the 2002 tsunami of Stromboli island (Italy), scaled down to $1 / 1000$. The 2002 Stromboli tsunami originated from two different landslides along the steep slope of Sciara del Fuoco, on the volcanic island of Stromboli, which generated waves in excess of $6 \mathrm{~m}$ (Tinti et al 2005).

At the onset of motion, the sliding mass pushes water ahead and an elevation wave is generated in front of it (Fig. 3 a). At the same time, a depression wave forms landward, where the shoreline retreats. While the elevation wave quickly disappears offshore, the depression at the back of the slide becomes deeper, creating large pressure gradients along the shore (Fig. $3 b, c$ ). Those gradients drive strong fluxes towards the centre just to fill the gap, resulting in a focussing effect which produces a large rebound wave. The latter eventually splits into two crests, which then start to propagate in an organised manner along the shoreline (Fig. $3 d$ ). This dynamics is consistent with the eyewitness accounts of the 2002 Stromboli tsunami, for which Tinti et al (2005) report: "the water withdrew, picked up sand, rose like a wall and then started propagating as an organized wave". Indeed, the wave field is made by an evanescent component quickly decaying offshore (Fig. $3 b, c$ ), and by a propagating longshore motion (Fig. $3 d$ ). The latter is responsible for tsunami devastation along the beach. The model results of Renzi and Sammarco (2012) were further compared with the experimental data of Di Risio et al (2009a), resulting in a very consistent validation exercise. The experiments were conducted at LIAM (Laboratory of Maritime and Environmental Hydraulics of L'Aquila, Italy) in a $5.40 \mathrm{~m}$ long by $10.80 \mathrm{~m}$ wide and $0.8 \mathrm{~m}$ 

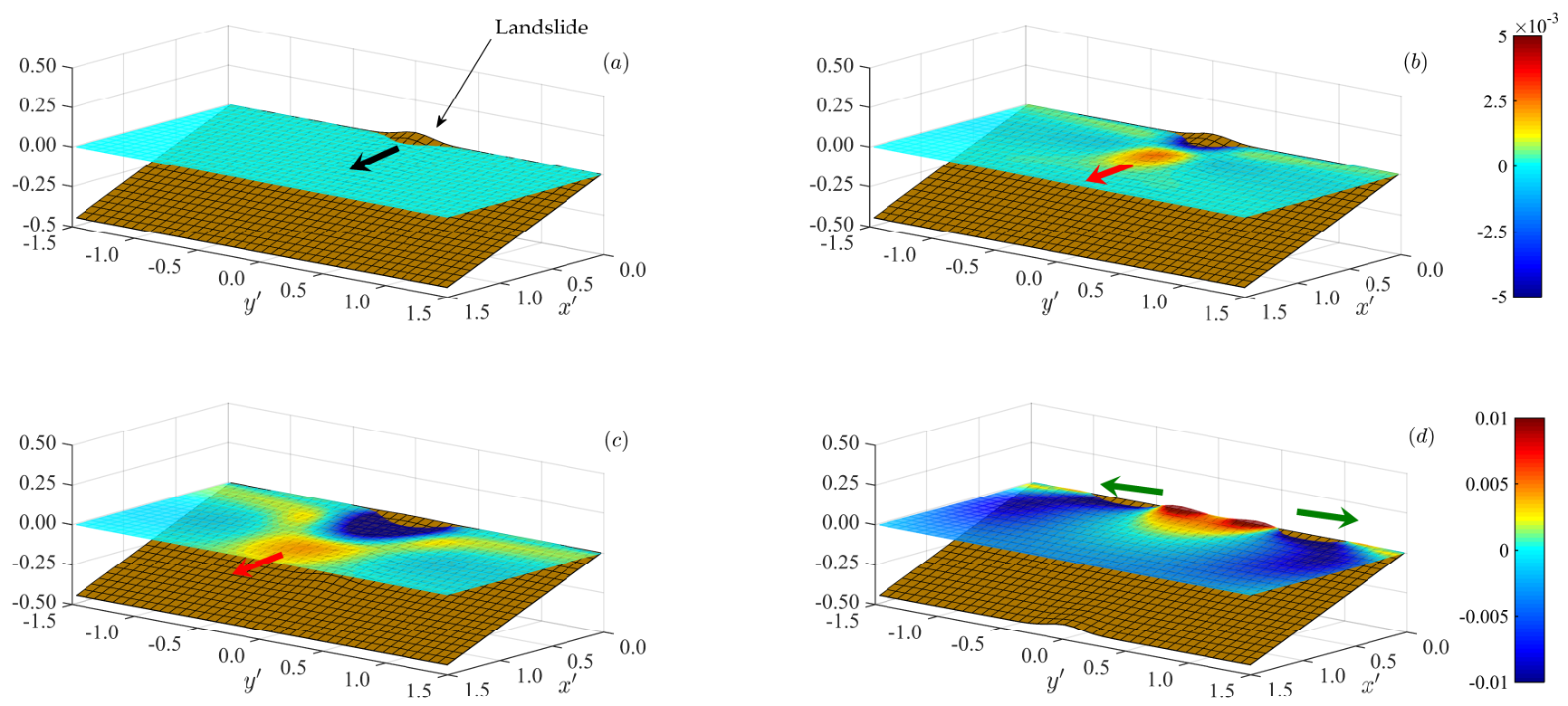

Fig. 3 Snapshot of the tsunami generated by a double Gaussian landslide along a plane beach. $(a) t^{\prime}=0.2 \mathrm{~s}$. The black arrow indicates the direction of motion of the landslide. $(b) t^{\prime}=0.2 \mathrm{~s}$, the red arrow indicates the direction of propagation of the offshore elevation wave (evanescent wave). ( $c$ ) $t^{\prime}=0.5 \mathrm{~s}$, again the red arrow indicates the direction of propagation of the evanescent wave. $(d) t^{\prime}=1.5 \mathrm{~s}$, the green arrows indicate the direction of propagation of the longshore trapped modes. Parameters are: $x_{g}^{\prime}=0 \mathrm{~m}, u_{g}^{\prime}=1 \mathrm{~m} / \mathrm{s}$. The first six modes have been considered. All values are in metres. After Renzi and Sammarco (2012).

Table 1 Gaussian landslide and beach geometry for the experimental comparison.

\begin{tabular}{lll}
\hline $\begin{array}{l}\text { Landslide char. length } \\
0.37 \mathrm{~m}\end{array}$ & Width & Thickness \\
& $0.185 \mathrm{~m}$ & $0.045 \mathrm{~m}$ \\
\hline Initial position & Mean speed & Beach slope \\
$-0.18 \mathrm{~m}$ & $0.845 \mathrm{~m} / \mathrm{s}$ & $1 / 3$ \\
\hline
\end{tabular}

deep basin. An ellipsoidal $0.8 \mathrm{~m}$ long by $0.4 \mathrm{~m}$ wide block was used, with a maximum thickness of $0.05 \mathrm{~m}$ and maximum cross-sectional area of $0.03 \mathrm{~m}^{2}$. If again $\sigma_{g}=0.37 \mathrm{~m}$, $\eta_{g}=0.045 \mathrm{~m}$ and $\lambda_{g}=0.185 \mathrm{~m}$, the overall area beneath the theoretical curve $f_{g}$ (Eq. 6) approximates the maximum cross-sectional area of the experimental landslide. The centroid initial position is now $x_{g}^{\prime}=-0.18 \mathrm{~m}$ and the mean speed is $u_{g}^{\prime}=0.845 \mathrm{~m} / \mathrm{s}$, in accordance with the experimental setup (see Table 1). Figure 4 shows the time series of the tsunami $\left(\zeta^{\prime}\right)$ generated by the landslide at two different points along the shoreline. The thin red line shows the experimental data, while the bold black line represents the model results, in very good agreement with the experiments. Note that at both locations the largest wave is never the first one, but is rather shifted towards the middle of the group. This interesting behaviour, also reported in several eyewitness accounts (Tinti et al 2005), results from the absence of a properly defined leading wave along a sloping beach, as shown analytically by Sammarco and Renzi (2008). Note that this delaying effect of
Table 2 Geometry of the double parabolic slide.

\begin{tabular}{lll}
\hline Landslide char. length & Width & Thickness \\
$0.44 \mathrm{~m}$ & $0.22 \mathrm{~m}$ & $0.045 \mathrm{~m}$ \\
\hline Initial position & Mean speed & Beach slope \\
$-0.18 \mathrm{~m}$ & $0.845 \mathrm{~m} / \mathrm{s}$ & $1 / 3$ \\
\hline
\end{tabular}

the tallest waves is a property of the plane beach bathymetry. For example, it does not occur over a flat bottom, where instead a proper leading elevation wave exists and has the shape of an Airy function (Mei et al 2005; Di Risio and Sammarco 2008; Sammarco and Renzi 2008). We finally note that this peculiar signature of landslide tsunamis along a beach can induce a distorted sense of safety. People might believe that the worst has passed after the first wave has stricken, only to be hit by a taller wave later.

Influence of the slide shape In order to analyse the influence of the slide shape on the generated wave field, Renzi and Sammarco (2012) modelled the same event as above (see again Fig. 4), but with the double parabolic landslide $f_{p}$ (Eq. 7 and Fig. 2) instead of the double Gaussian one. The slide parameters, reported in Table 2, are set so that the doubleparabolic slide maximum cross sectional area approximates that of the double Gaussian slide of Table 1. Direct comparison of the free-surface elevation $\zeta^{\prime}$ in the two cases reveals a general correspondence between the two wave fields, as 

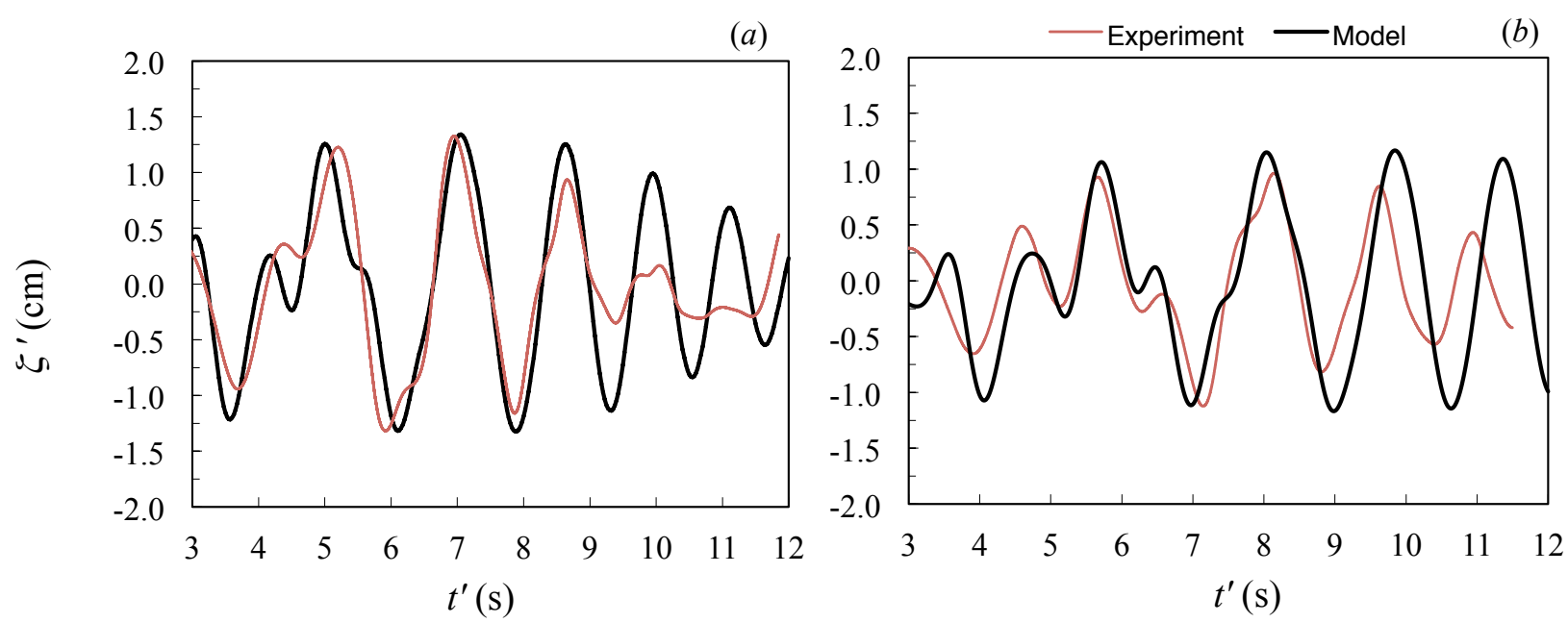

Fig. 4 Time series of the tsunami generated by the double Gaussian landslide of Table 1 . $(a)$ On the shoreline $\left(x^{\prime}=0 \mathrm{~m}\right)$ at $y^{\prime}=3.10 \mathrm{~m}$ away from the impact area. $(b)$ On the shoreline $\left(x^{\prime}=0 \mathrm{~m}\right)$ at $y^{\prime}=4.07 \mathrm{~m}$ away from the impact area. Note that the experimental data deteriorate after $t^{\prime}=8 \mathrm{~s}$ because of wave reflection from the sidewalls. After Renzi and Sammarco (2012).

shown in Fig. 5. However, while the perturbation induced by the Gaussian slide is smooth, the wave field generated by the double parabolic slide is characterised by the occurrence of spiky double-crested waves. The latter are likely caused by the secondary inertial rebound occurring soon after the tail of the slide enters water (Renzi and Sammarco 2012). Such an effect is mostly enhanced for sharp bodies, like the double parabolic slide, rather than for blunt bodies like the Gaussian slide. Therefore, the presence of irregularities in the shape of the landslide can favour the generation of potentially more destructive double-crested waves.

Influence of the continental shelf Renzi and Sammarco (2012) also analysed the dynamics of landslide tsunami generation and propagation along a semi-plane beach, where the slope extends to a finite length $b^{\prime}$ and then connects to a continental shelf of constant depth $h_{b}^{\prime}=s b^{\prime}$. A sketch of the semi-plane beach geometry is shown in Fig. 6. By using the method of matched eigenfunction expansion, Renzi and Sammarco (2012) surprisingly found that all the natural shallow-water modes of the semi-plane beach are still trapped along the shoreline, in the form of edge waves, just like it happens with a plane beach. The only noticeable influence of the continental shelf is that it lowers the number of eigenmodes to a finite amount with respect to those excited along a plane beach, which instead are infinite. As a consequence, landslide tsunamis generated along a semi-plane beach tend to be less energetic than those along an infinite slope. To better appreciate such difference, Renzi and Sammarco (2012) took the same Gaussian landslide of Table 1, with $x_{g}=0$, $u_{g}=1$, but sliding along a finite incline of slope $s=1 / 3$ and length $b^{\prime}=0.37 \mathrm{~m}$, connecting to a continental platform of depth $h_{b}^{\prime}=0.123 \mathrm{~m}$. The solid lines of Fig. 6 show the time series of the tsunami $\left(\zeta^{\prime}\right)$, at points A ( $0.4 \mathrm{~m}$ offshore) and $\mathrm{B}$ (0.8 $\mathrm{m}$ alonghsore), respectively. In the same figure, Renzi and Sammarco (2012) plotted the time series of the free-surface elevation obtained at the same points, but for an indefinite plane beach. As anticipated, the wave field generated in the semi-plane beach is less energetic. This happens since for small beach lengths $\left(b^{\prime} \simeq \sigma\right)$ only the first beach modes are excited and concur to generate the propagating tsunami. Therefore, the presence of a continental shelf at the end of a relatively short beach (i.e. whose length is comparable to the landslide length) might be beneficial in reducing the tsunami energy.

\subsection{Conical island model (Renzi and Sammarco 2010)}

Tsunami propagation in cylindrical geometries can be much more puzzling than that along a straight coastline. For example, one might think that an island would act as a natural shelter, protecting those sectors of the shoreline which are radially opposite to the area of tsunami generation: this is far from reality. Indeed, during the 1992 Flores island tsunami, unexpectedly large runup occurred in the lee side of the Babi island, impacting areas normally protected from swell waves (Bardet et al 2003; Kanoglu and Synolakis 2015). The mathematical model of landslide tsunami generation and propagation around a conical island of Renzi and Sammarco (2010) shows that edge-wave like modes are excited and travel around the shore. This explains why part of the tsunami energy can be trapped around the shoreline, thus 

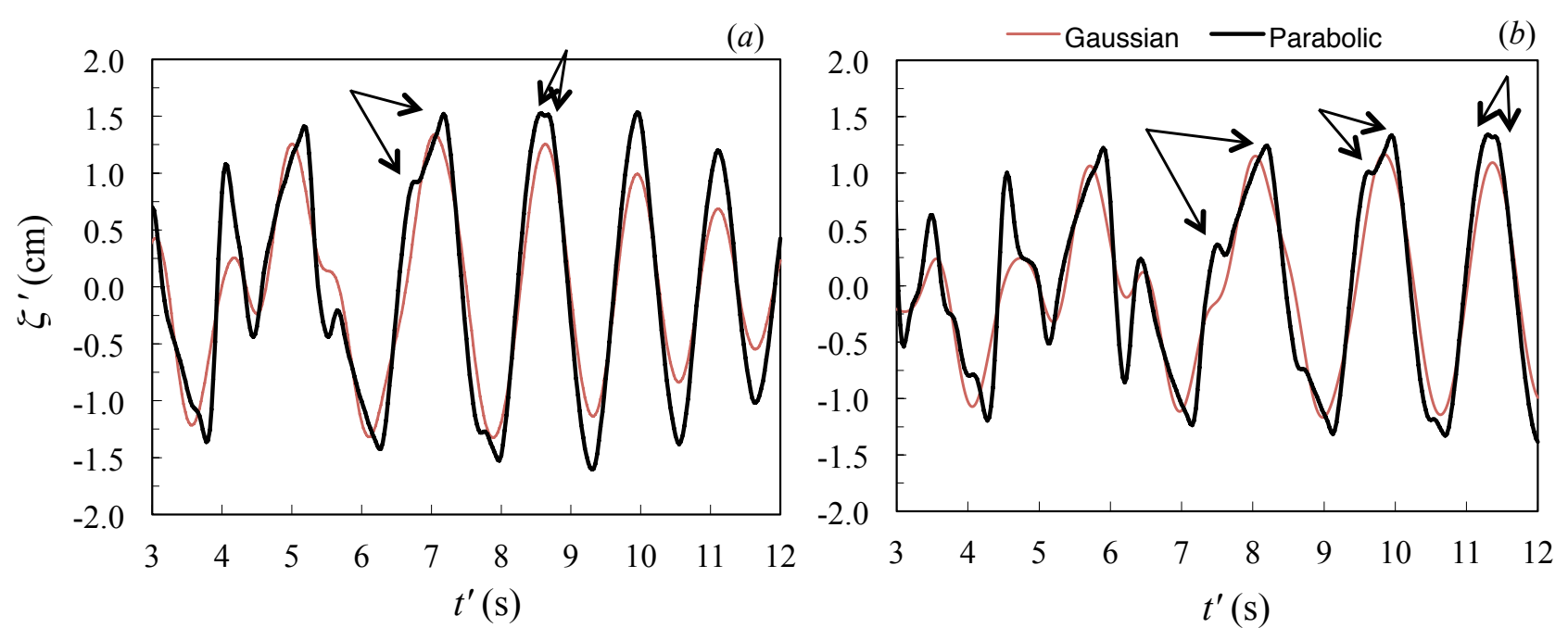

Fig. 5 Time series of the tsunami generated by the double Gaussian landslide of Table 1 and by the double parabolic slide of Table 2. ( $a$ ) On the shoreline $\left(x^{\prime}=0 \mathrm{~m}\right)$ at $y^{\prime}=3.10 \mathrm{~m}$ away from the impact area. $(b)$ On the shoreline $\left(x^{\prime}=0 \mathrm{~m}\right)$ at $y^{\prime}=4.07 \mathrm{~m}$ away from the impact area. The arrows indicate where double-crested waves occur. After Renzi and Sammarco (2012).

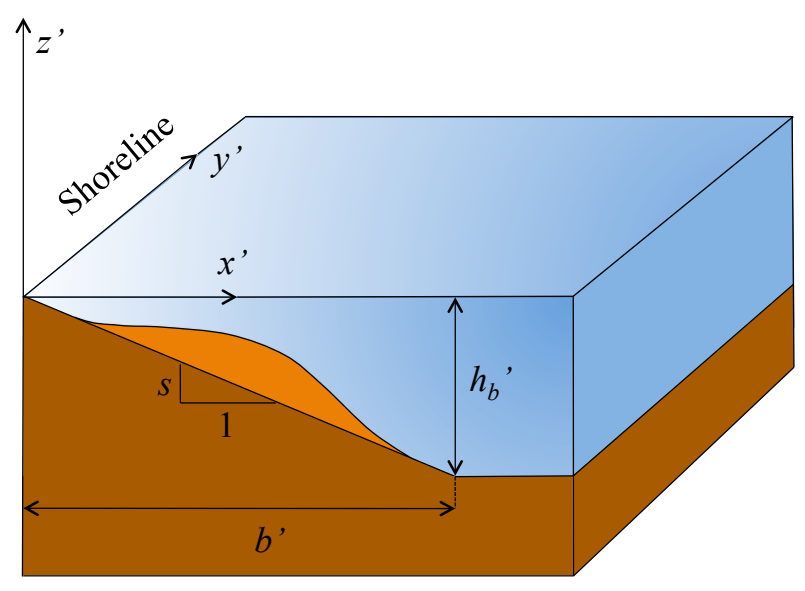

Fig. 6 Semi-plane beach and landslide in physical variables.

producing enhanced runup while the waves circle around the island.

Mathematical formulation Referring to Fig 8, let us consider a conical island of bottom radius $b^{\prime}$ on a continental platform of constant depth $h_{b}^{\prime}$. The forced linear shallow-water equation now reads

$\zeta_{t^{\prime} t^{\prime}}^{\prime}-g h^{\prime}\left(\frac{1}{r^{\prime}} \zeta_{r^{\prime}}^{\prime}+\zeta_{r^{\prime} r^{\prime}}^{\prime}+\frac{1}{r^{\prime 2}} \zeta_{\theta \theta}^{\prime}\right)-g h_{r^{\prime}}^{\prime} \zeta_{r^{\prime}}^{\prime}=f_{t^{\prime} t^{\prime}}^{\prime}$

where the notation is the same as that of Section 3.1, but for $r^{\prime}$ the radial coordinate and $\theta$ the angular coordinate, positive if counter-clockwise. The undisturbed water depth is $h^{\prime}=s\left(r^{\prime}-r_{0}^{\prime}\right)$ if $r_{0}^{\prime}<r^{\prime}<b^{\prime}$ and $h^{\prime}=h_{b}^{\prime}$ otherwise, where $r_{0}^{\prime}$ is the radius of the wetted island contour (see again figure 8 ). Let again $2 \sigma, 2 \lambda$ and $\eta$ be, respectively, the landslide characteristic length, width and thickness. Then the same non-dimensional variables as in Eq. 3 can be defined, but with $r^{\prime}$ instead of $x^{\prime}$, i.e. $r^{\prime}=x^{\prime} / b^{\prime}$. By combining the Laplace transform with the methods of separation of variables and matching expansions, the solution of Eq. (8) was found for a double Gaussian landslide of shape

$f(r, \theta, t)=\exp \left\{-\left[r-r_{c}(t)\right]^{2}-(\gamma \theta)^{2}\right\}$.

In the latter, $r_{c}(t)$ is the radial coordinate of the centroid and $\gamma=1 / \theta_{0}, \theta_{0}=2 \lambda / r_{c}(0)$ being the characteristic angle subtended by the landslide at its starting position. Along the island flanks $\left(r_{0}<r<b\right)$, the free-surface elevation was found to be

$$
\begin{aligned}
\zeta(r, \theta, t) & =\sum_{n=0}^{\infty} \cos n \theta \int_{0}^{\infty}\left[A_{n}(r, \omega) H c_{n}^{(1)}(r, \omega)\right. \\
& \left.+B_{n}(r, \omega) H c_{n}^{(2)}(r, \omega)\right] e^{-i \omega t} d \omega+c . c .
\end{aligned}
$$

where $c . c$. is the complex conjugate, $n$ denotes the angular modes and $\omega$ is the wave frequency. The $A_{n} \mathrm{~s}$ and $B_{n} \mathrm{~s}$ in Eq. 10 are frequency-varying modal shape functions depending on the geometry of the system (for detailed expressions see Section 3.3 of Renzi and Sammarco 2010). Finally, $H c_{n}^{(1,2)}$ is the Confluent Heun function of first (second) kind and order $n$, solution of the Confluent Heun equation, which is a second-order ODE with two finite regular singular points and an irregular singular point at infinity. Solution 10 is a first-time application of the Confluent Heun functions as the natural solutions of the problem of tsunami propagation 

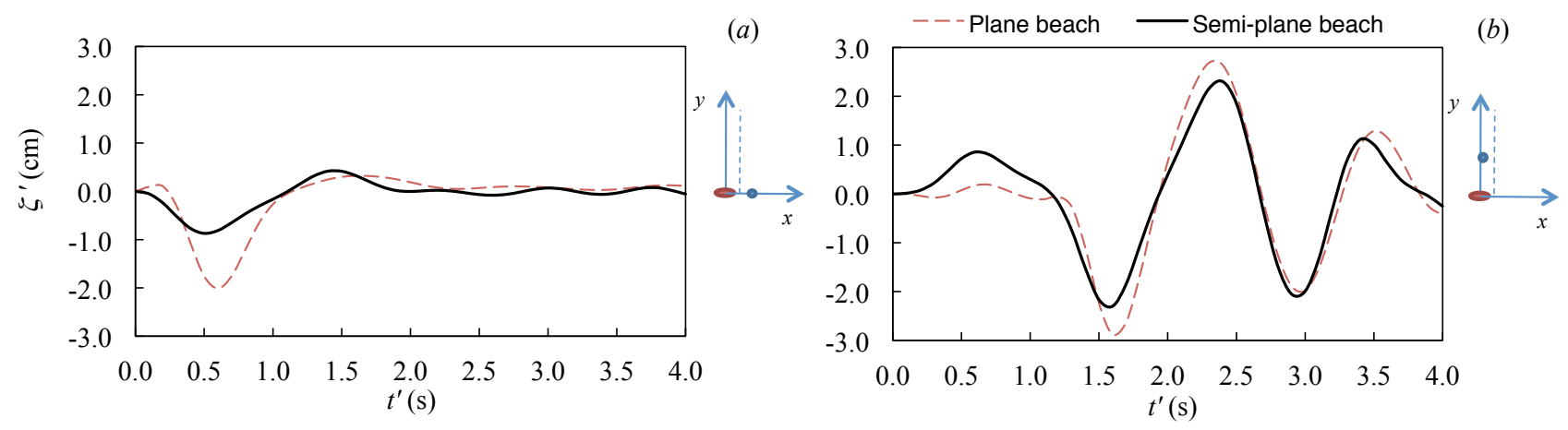

Fig. 7 Time series of the tsunami generated by the double Gaussian landslide of Table 1 both on an indefinite plane beach and on a semi-plane beach. (a) Point A at $y^{\prime}=0 \mathrm{~m}$ and $x^{\prime}=0.4 \mathrm{~m}$ offshore from the impact area. $(b)$ Point B on the shoreline $\left(x^{\prime}=0 \mathrm{~m}\right)$ at $y^{\prime}=0.8 \mathrm{~m}$ away from the impact area. After Renzi and Sammarco (2012).

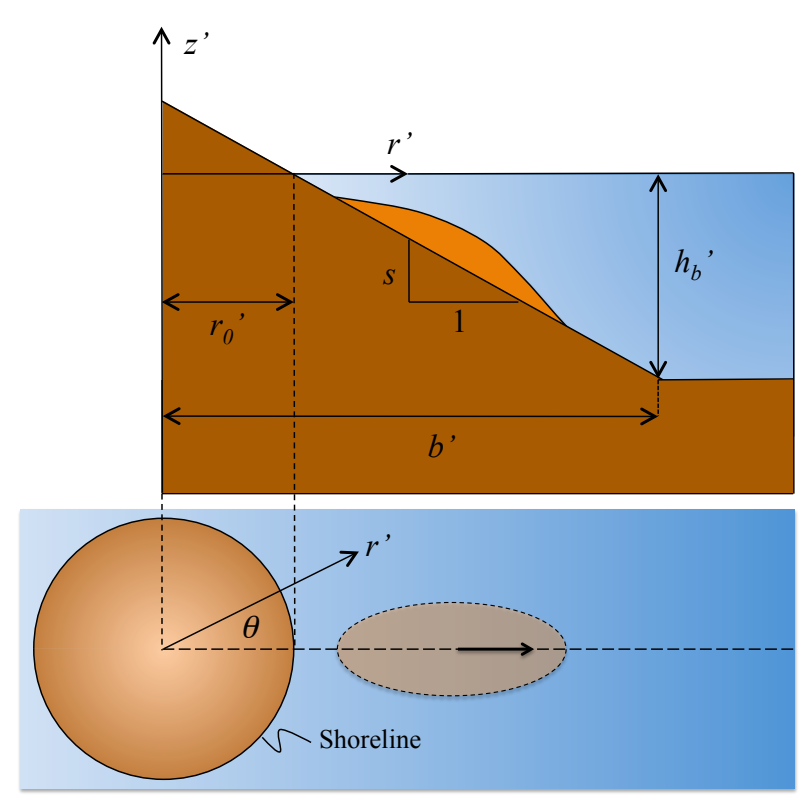

Fig. 8 Conical island geometry in physical variables. Upper panel: radial section. Lower panel: plan view.

in a conical geometry (Eq. 8). On the other hand, on the continental platform $(r>b)$ the free-surface elevation was found to be

$\zeta(r, \theta, t)=\sum_{n=0}^{\infty} \cos n \theta \int_{0}^{\infty} C_{n}(\omega) H_{n}\left(\frac{\omega r}{\sqrt{h_{b}}}\right) d \omega+c . c .$,

where $C_{n}$ is a frequency-varying modal shape function which depends on the slide parameters (for the detailed expression of $C_{n}$ see Section 3.3 of Renzi and Sammarco 2010). In Eq. 11 $H_{n}$ is the Hankel function of first kind and order $n$, outgoing at large distance from the island (Mei 1997). The presence of outgoing terms in Eq. 11 implies that transient waves are
Table 3 Island and landslide geometry

\begin{tabular}{lll}
\hline Island wet contour & Slope & Bottom radius \\
$2.07 \mathrm{~m}$ & $1 / 3$ & $4.45 \mathrm{~m}$ \\
\hline Slide char. length & Width & Thickness \\
$0.175 \mathrm{~m}$ & $0.0875 \mathrm{~m}$ & $0.045 \mathrm{~m}$ \\
\hline
\end{tabular}

indeed capable of escaping the island towards the far field. That contrasts with the perfect trapping of a plane beach, where shallow-water waves cannot escape at all (see again Section 3.1). Indeed, landslide-generated tsunamis around a conical island are not perfectly trapped. As a consequence, there exists a transient leading wave propagating radially, which Renzi and Sammarco (2010) showed to be time decaying as $O\left(t^{-1 / 2}\right)$. That is quicker than the decay of the leading wave in a two-dimensional ocean of constant depth, $O\left(t^{-1 / 3}\right)$ (Mei et al 2005). Such a quick decay of the offshore leading wave in the conical island geometry implies that much of the tsunami energy is still held around the island, whose beach acts as a barrier to partially trap waves. In the following section, we shall comment on the dynamics of generation and propagation of a tsunami induced by a double Gaussian landslide around a conical island, resembling the 2002 event at Stromboli (Tinti et al 2005).

Tsunami generation and propagation Figure 9 shows the time series of the runup generated by the double Gaussian slide of Eq. 9 along an island of wet contour $r_{0}^{\prime}=2.07 \mathrm{~m}$, slope $s=1 / 3$ and bottom radius $b^{\prime}=4.45 \mathrm{~m}$. The landslide characteristic length and width are, respectively, $\sigma=0.175$ $\mathrm{m}$ and $\lambda=0.0875 \mathrm{~m}$, while the thickness is $\eta=0.045 \mathrm{~m}$ (see Table 3). The initial position of the slide is $r_{c}^{\prime}(0)=1.3 \mathrm{~m}$. Those dimensions correspond nearly to the geometry of the physical model designed by Di Risio et al (2009b), which reproduces the 2002 tsunami at Stromboli on a 1:1000 Froude 

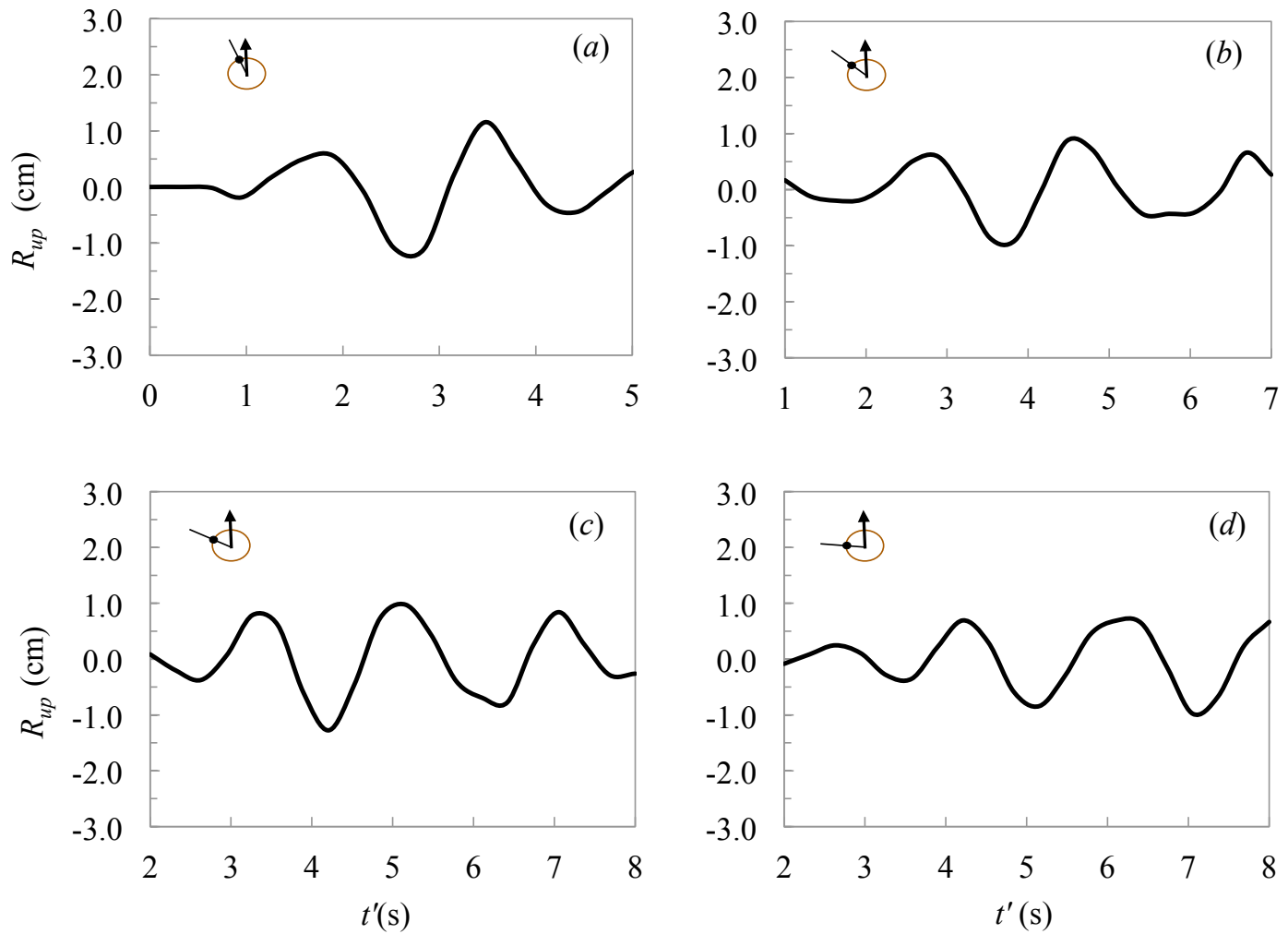

Fig. 9 Time series of the tsunami generated by the double Gaussian landslide of Table 3 at four points along the shore. $(a) \theta_{1}=20.6$ deg from the impact area, $(b) \theta_{2}=47.6 \mathrm{deg},(c) \theta_{3}=60.2 \mathrm{deg}$ and $(d) \theta_{4}=86.3 \mathrm{deg}$. After Renzi and Sammarco (2010).

scale. Figure $9(a)$ refers to $\theta_{1}=20.6 \mathrm{deg}$, corresponding to $0.72 \mathrm{~m}$ from the origin of the landslide. Moving away from the point of tsunami generation, Fig. $9(b)$ corresponds to $\theta_{2}=47.6 \mathrm{deg}$, about $1.24 \mathrm{~m}$ from the origin, while Fig. 9(c) refers to $\theta_{3}=60.2 \mathrm{deg}$, about $2.17 \mathrm{~m}$ from the origin. Finally, Fig. $9(d)$ corresponds to $\theta_{4}=86.3 \mathrm{deg}$, approximately 2.17 $\mathrm{m}$ from the origin. Let us first consider those points closer to the landslide, where $\theta$ ranges from $\theta_{1}$ to $\theta_{3}$ (Fig. $9 a$ c). Like on a plane beach (see again Fig. 3), close to the origin the water at first recedes, due to the generation of a deep depression wave at the back of the slide. The through is then followed by a large crest, resulting from the inertial rebound due to the focussing of fluxes towards the origin. Note that the model wave period is about $2 \mathrm{~s}$ and the maximum runup is $0.01 \mathrm{~m}$, which in nature would correspond to about $63 \mathrm{~s}$ and $10 \mathrm{~m}$, respectively, according to the chosen Froude scale. This is consistent with the report of Tinti et al (2005) for the 2002 tsunami at Stromboli. Moving far from the landslide at $\theta_{4}$, the first wave has a small crest, followed by larger oscillations (see Fig. $9(d)$ ). Again, the largest wave is shifted towards the middle of the group, as it occurs along a plane beach, where this phenomenon is associated with the excitation of edge-wave modes trapped along the shoreline. This suggests that edge-wave like components of the wave motion can be partially trapped around a conical island, leading to large runup even at locations normally sheltered from swell waves. The theoretical findings of Renzi and Sammarco (2010) were later confirmed experimentally by Romano et al (2013). By using new high-resolution experimental datasets, Romano et al (2013) found that the runup time series of landslide tsunamis around a circular island indeed contain waves resembling the 0th-order edge wave mode. This result has significant practical importance, as a simple formula like the 0th order edge wave dispersion relation (Eq. 5 with $n=0$ ) could be used to obtain a quick estimate of the tsunami period and speed (Romano et al 2013).

\section{Discussion and new research directions}

Moving from theory to practice, the development of a tsunami early-warning system (TEWS) for coastal landslides is still a challenge Cecioni et al (2011); De Girolamo et al (2011, 2014). First, the origin of a landslide tsunami is near the shoreline, so that the tsunami propagates very quickly into coastal areas, as in the case of the Sissano lagoon (Farrell et al 2015). This makes the need for timely warning an issue of paramount importance. Unfortunately, such a requirement 
competes against the need for long computational time to run complex inundation prediction models. Second, such models are always associated with some degree of uncertainty, due to uncertain trigger characteristics (e.g. position, shape and motion of the landslide). This leads to significant delays in tsunami warning and makes estimating the uncertainty impractical. Here is where analytical models prove their importance. Based on the analytical model of Sammarco and Renzi (2008), Sarri et al (2012) built a fast statistical emulator which enables one to obtain tsunami estimates almost instantaneously. The Sarri et al (2012) emulator is capable of producing 1000 tsunami runup evaluations in as little as 83.9 seconds, providing accurate results quickly in situations where early warnings are necessary.

From a modelling point of view, a limitation of the analytical models of Sammarco and Renzi (2008), Renzi and Sammarco (2010) and Renzi and Sammarco (2012) is the absence of bottom friction and slide deformation. Wang et al (2011) derived an improved landslide tsunami model which considers solid friction, lubricative resistance and hydrodynamic pressure on the slide. The model of Wang et al (2011) shows that resistance, size and speed of the slide play a major role in determining the runup on a two-dimensional (2D) plane beach. A drawback of the 2D model of Wang et al (2011) is the impossibility of modelling 3D effects, like transient longshore edge waves. Mohammed and Fritz (2012) explored the effect of slide deformation by using deformable granular landslides in a 3D physical model. They found that the tsunami wave profile depends mainly on the landslide thickness, width and length, thus in general agreement with the solid-block analytical results of Sammarco and Renzi (2008). An interesting effect of slide deformation is the generation of nonlinear trailing waves by superposition of slow flux of thinning landslide material and shoreline oscillations near the impact zone (Mohammed and Fritz 2012). Such a dynamics could be modelled via a weakly nonlinear extension of the analytical theory of Sammarco and Renzi (2008), with the addition of a deforming landslide.

Concerning the propagation of tsunamis around islands, recently Stefanakis et al (2014) have shown that focussing effects of incident waves around circular islands can lead to unexpected large runup behind the lee side, instead of protecting it. The hydrodynamic problem of tsunami generation in a circular geometry has been also considered by Stefanakis et al (2015), who analysed the generation of waves by an uplifting circular sill. Stefanakis et al (2015) found that partial wave trapping reduces the wave height in the far field, while amplifying it near the sill, in perfect agreement with the analytical model of Renzi and Sammarco (2010).

One recent research direction points at investigating the effect of enclosures on the propagation of landslide tsunami waves. By using a nonlinear model equation in a Lagrangian reference frame, Couston et al (2015) investigated the runup of a landslide tsunami in a lake. They found that constructive interference between longshore edge waves and multiple reflections of transient waves from the lakeshore can magnify the highest runup. This explains the unusual runup recorded in the Lituya bay event of July 9, 1958.

Another interesting research direction points to the use of acoustic precursors for the early detection of tsunamis. Underwater acoustic (hydro-acoustic) waves are generated by seafloor movements together with tsunami waves (Synolakis et al 2002; Hendin and Stiassnie 2013) and travel at a speed close to the speed of sound in water, about $1500 \mathrm{~m} / \mathrm{s}$. That is much larger than the speed of typical landslide tsunami waves, e.g. about $28 \mathrm{~m} / \mathrm{s}$ for the 2002 Stromboli tsunami (Romano et al 2013). This suggest that hydro-acoustic waves can be used as precursors for the early detection of tsunamis. Recently, Sammarco et al (2013) and Renzi et al (2015) have derived model equations of hydro-acoustic wave generation by bottom displacements within the framework of a mildslope theory (Mei et al 2005). Cecioni et al (2015) have applied the MSEWC model of Sammarco et al (2013) to real large-scale scenarios, confirming the feasibility of earthquake TEWS based on the detection of hydro-acoustic waves with submarine hydrophone stations. Application of this technique to landslide tsunamis is envisaged as an intriguing development.

\section{References}

Bardet JP, Synolakis CE, Davies HL, Imamura F, Okal EA (2003) Landslide tsunamis: Recent findings and research directions. Pageoph Topical Volumes pp 1793-1809

Cecioni C, Romano A, Bellotti G, Di Risio M, De Girolamo P (2011) Real-time inversion of tsunamis generated by landslides. Nat Hazards Earth Syst Sci 11:2511-2520

Cecioni C, Abdolali A, Bellotti G, Sammarco P (2015) Large-scale numerical modeling of hydro-acoustic waves generated by tsunamigenic earthquakes. Nat Hazards Earth Syst Sci 15:627-636

Couston LA, Mei CC, Alam MR (2015) Landslide tsunamis in lakes. J Fluid Mech 772:784-804

De Girolamo P, De Bernardinis B, Beltrami GM, Di Risio M, Bellotti G, Capone $\mathrm{T}$ (2011) The Italian activities on tsunami risk mitigation: the operating landslide tsunami early warning system of Stromboli (Aeolian Islands, Italy). In: Proceedings of the 7th International Workshop on Coastal Disaster Prevention, Tokyo

De Girolamo P, Di Risio M, Romano A, Molfetta M (2014) Landslide tsunami: physical modeling for the implementation of tsunami early warning systems in the Mediterranean Sea. Procedia Engineering 70:492-438

Di Risio M, Sammarco P (2008) Analytical modeling of landslidegenerated waves. J Waterway, Port, Coastal, Ocean Eng 134:53-60

Di Risio M, Bellotti G, Panizzo A, De Girolamo P (2009a) Threedimensional experiments on landslide generated waves at a sloping coast. Coast Eng 56(5-6):659-671

Di Risio M, De Girolamo P, Bellotti G, Panizzo A, Aristodemo F, Molfetta M, Petrillo A (2009b) Landslide-generated tsunamis runup at the coast of a conical island: new physical model experiments. $\mathrm{J}$ Geophys Res 114(C01009) 
Dias F, Dutykh D, O’Brien L, Renzi E, Stefanakis T (2014) On the modelling of tsunami generation and tsunami inundation. Procedia IUTAM (10):338-355

Farrell EJ, Ellis JT, Hickey KR (2015) Tsunami case studies. In: Ellis JT, Sherman DJ (eds) Coastal and Marine Hazards, Risks, and Disasters, Elsevier, Amsterdam, pp 93-128

Hendin G, Stiassnie M (2013) Tsunami and acoustic-gravity waves in water of constant depth. Phys Fluids 25(086103):1-20

Kanoglu U, Synolakis C (2015) Tsunami dynamics, forecasting, and mitigation. In: Ellis JT, Sherman DJ (eds) Coastal and Marine Hazards, Risks, and Disasters, Elsevier, Amsterdam, pp 15-57

Liu PLF, Lynett P, Synolakis CE (2003) Analytical solutions for forced long waves on a sloping beach. J Fluid Mech 478:101-109

Liu PLF, Wu TR, Raichlen F, Synolakis CE, Borrero JC (2005) Runup and rundown generated by three-dimensional sliding masses. $\mathbf{J}$ Fluid Mech 536:107-144

Lynett P, Liu PLF (2005) A numerical study of the run-up generated by three-dimensional landslides. J Geophys Res 110(C03006):1-16

Ma G, Shi F, Kirby JT (2012) Shock-capturing non-hydrostatic model for fully dispersive surface wave processes. Ocean Model 43-44:2235

Ma G, Kirby JT, Shi F (2013) Numerical simlation of tsunami waves generated by deformable submarine landslides. Ocean Model 69:146-165

Mei CC (1997) Mathematical Analysis in Engineering. Cambridge University Press

Mei CC, Stiassnie M, Yue DKP (2005) Theory and application of ocean surface waves. World Scientific, Singapore

Mohammed F, Fritz H (2012) Physical modeling of tsunamis generated by three-dimensional deformable granular landslides. J Geophys Res 11(C11)

Panizzo A, De Girolamo P, Di Risio M, Maistri A, Petaccia A (2005) Great landslide events in Italian artificial reservoirs. Nat Hazards Earth Syst Sci 5:733-740

Renzi E (2010) Landslide tsunamis. PhD thesis, University of Rome Tor Vergata

Renzi E, Sammarco P (2010) Landslide tsunamis propagating around a conical island. J Fluid Mech 605:251-285

Renzi E, Sammarco P (2012) The influence of landslide shape and continental shelf on landslide generated tsunamis along a plane beach. Nat Hazards Earth Syst Sci 12:1503-1520

Renzi E, Cecioni C, Bellotti G, Sammarco P, Dias F (2015) Extended mild-slope equations for compressible fluids. In: Proceedings of the 30th IWWWFB, Bristol, UK

Romano A, Di Risio M, Bellotti G (2013) Wavenumber-frequency analysis of the landslide-generated tsunamis at a conical island. Coast Eng 81:32-43

Sammarco P, Renzi E (2008) Landslide tsunamis propagating along a plane beach. J Fluid Mech 598:107-119

Sammarco P, Cecioni C, Bellotti G, Abdolali A (2013) Depth-integrated equation for large-scale modelling of low-frequency hydroacoustic waves. J Fluid Mech 722(R6):1-10

Sarri A, Guillas S, Dias F (2012) Statistical emulation of a tsunami model for sensitivity analysis and uncertainty quantification. Nat Hazards Earth Syst Sci 12:2003-2018

Stefanakis T, Contal E, Vayatis F, Dias F, Synolakis CE (2014) Can small islands protect nearby coasts from tsunamis? An active experimental design approach. Proc R Soc A 470(20140575)

Stefanakis T, Dias F, Synolakis C (2015) Tsunami generation above a sill. Pure Appl Geophys 172(3-4):985-1002

Synolakis CE, Bardet JP, Borrero JC, Davies HL, Okal EA, Silver E, Sweet S, Tappin DR (2002) The slump origin of the 1998 Papua New Guinea tsunami. Proc R Soc A 458:763-789

Tappin DR, Watts P, Grilli ST (2008) The Papua New Guinea tsunami of 17 July 1998: anatomy of a catastrophic event. Nat Hazards Earth Syst Sci 8:243-266
Tehranirad B, Harris JC, Grilli AR, Grilli ST, Abadie S, Kirby JT, Shi F (2015) Far-field tsunami impact in the north atlantic basin from large scale flank collapses of the cumbre vieja volcano, la palma. Pure Appl Geophys pp 1-28

Tinti S, Manucci A, Pagnoni G, Armigliato A, Zaniboni F (2005) The 30 december 2002 landslide-induced tsunamis in Stromboli: sequence of the events reconstructed from the eyewitness accounts. Nat Hazards Earth Syst Sci 5:763-775

Wang Y, Liu PLF, Mei CC (2011) Solid landslide generated waves. J Fluid Mech 675:529-539

Watts P, Grilli ST, Kirby JT, Fryer GJ, Tappin DR (2003) Landslide tsunami case studies using a boussinesq model and a fully nonlinear tsunami generation model. Nat Hazards Earth Syst Sci 3(391-402) 